\section{Diagnostic biopsy of melanoma: primary or secondary care?}

Murchie et al compared morbidity and mortality in patients who had initial diagnostic excision biopsy in primary versus secondary care. The Breslow thickness of a melanoma is the main prognostic indicator in the melanoma patients included in this study. The mean thickness in both the primary and secondary care groups was $\leq 1 \mathrm{~mm}$ : such patients have a 95\% 10-year survival rate, ${ }^{2}$ so that mortality and morbidity are not particularly relevant endpoints.

Suspected melanoma is best managed in secondary care because meeting a patient at their initial clinic visit and diagnostic biopsy allows a more informed discussion at the MDT, leading to better management, and if the melanoma is diagnosed in secondary care, we can ensure that breaking of bad news' is made by a clinician or skin cancer support nurse, who have the knowledge and experience to explain the prognostic significance of the melanoma, the MDT decisions and the further treatments required.

We have looked at patients who had GP melanoma excisions in our region. In 70\% of cases no clinical diagnosis was given on the pathology form, which may affect the interpretation of the pathology and the speed with which the material is processed. To improve lesion recognition and management by GPs in our region, GPs are invited to sit in on our weekly rapid access tumour clinics. We also plan to distribute a bi-monthly presentation of 'lesion pictures' to all GPs. A 'minor surgery interest group' has been formed who will meet annually to improve lesion recognition and management and to promote regional skin cancer pathways and communication between GPs and the local skin cancer team. We advise that suspicious pigmented lesions are referred urgently to secondary care. We hope our education programme will improve the experience of the patient, the GP and the secondary care physician involved in management of skin cancer patients.

\section{Mowbray,}

Consultant Dermatologist, Queen Margaret Hospital, Dunfermline.
Jinah Yoo,

Dermatology Registrar, Lauriston Building,

Edinburgh.

E-mail: Jinah. Yoolanhslothian.scot.nhs.uk

\section{REFERENCES}

1. Murchie P, Raja AE, Lee AJ, Campbell NC. Mortality and morbidity after initial diagnostic excision biopsy of cutaneous melanoma in primary versus secondary care. Br J Gen Pract 2013; doi:10.3399/ bjgp13X670697

2. Balch CM, Gershenwald JE, Soong SJ, et al. 2009 AJCC Melanoma Classification and Staging. J Clin Oncol 2009; 27(36): 6199-6206.

\section{DOl: 10.3399/bjgp14X676302}

\section{Authors' response}

We disagree with the correspondents comment that, since the mean thickness in both the primary and secondary care groups was $\leq 1 \mathrm{~mm}$, mortality and morbidity are not particularly relevant endpoints. We presented median and not mean values in our paper. In fact, over $40 \%$ of the lesions in each group of our study had a Breslow thickness $\geq 1 \mathrm{~mm}$. Furthermore, patients can die from melanoma irrespective of the Breslow thickness of the primary lesion, so mortality was the most appropriate primary outcome for our study. Similarly, morbidity, in this case, subsequent hospital attendances, must be included in any analysis where questions of surgical competence are being addressed.

We salute the excellent model of care that the corresponders are advocating, and implementing. However, they do not appear to provide any evidence as to why high quality skin biopsy of suspicious pigmented lesions in primary care could not be incorporated. We re-assert our conclusion that our study clearly signifies the need for a randomised controlled trial to establish the role of initial excision biopsy in primary care in the diagnosis and treatment of cutaneous melanoma in the UK. In the long run, this may be beneficial for both patients and the NHS.

\section{Peter Murchie,}

Division of Applied Health Science, University of Aberdeen, Aberdeen.

E-mail: p.murchielabdn.ac.uk
E Amalraj Raja, Amanda J Lee, Neil C Campbell

Division of Applied Health Science, University of Aberdeen, Aberdeen.

DOI: 10.3399/bjgp14X676311

\section{The future of elderly care in Turkey}

Although elderly and end-of-life care have been neglected in Turkey, because older people did not constitute a high percentage of the population, the proportion of citizens aged $>65$ years is now $7.5 \%$, with this proportion expected to increase to $10.2 \%$ by $2023,21 \%$ by 2050 and $28 \%$ by $2075 .{ }^{1}$ These estimates put Turkey as one of the most rapidly ageing populations in the world and have stimulated research and discussions around healthy ageing, chronic disease management and elderly care.

Turkey has also started to observe and analyse how other countries have managed this situation. Advance care planning has also been a topic of discussion for the older population. The UK has been one of the countries that have put efforts into better care of older people, and recent publications in the $B J G P$ have inspired us. ${ }^{2,3}$

The family medicine model has been fully implemented in Turkey since 2010. The new model allows doctors to have their own registered patients and the most reliable data in Turkey relies on the medical records of these registries. The opportunity here lies in the recognition of the transitions in people's lives, as described by Eynon et al..$^{3}$ The unique relation of GPs with their patients and the enthusiasm of the new model facilitates communication and gives time to speak on the topics that were not previously touched.

When is the right time to discuss advance care planning? We think that earlier is better, when people are still healthy and can make sound decisions. For a population still young, but ageing very rapidly as in Turkey, discussions around advanced directives have already been started. ${ }^{4}$ Such a move is likely to overcome the challenges Sharp et almention, such as families, time, patient reluctance, or dementia. ${ }^{2}$

It is not easy to talk on these topics. The fear and discomfort experienced by the GP might 
be added to the avoidance by the patient and care givers. We have very recently run a study to explore views of healthcare professionals and patients on end-of-life decisions, and found that both sides were not comfortable in talking about end-of life or even filling in a questionnaire on this topic. This remains as a challenge to overcome.

Turgay Albayrak, Rabia Kahveci,

Ankara Numune Training and Research Hospital, Department of Family Medicine, Ankara, Turkey.

\section{E-mail: turalbayraklagmail.com}

Adem Özkara,

Ankara Numune Training and Research Hospital, Department of Family Medicine, Ankara and Hitit University, Department of Family Medicine, Corum, Turkey.

Ismail Kasım,

Ankara Numune Training and Research Hospital, Department of Family Medicine, Ankara, Turkey.

\section{REFERENCES}

1. Turkish Statistical Institute. Population Projections, 2013-2075. http://uww.turkstat.gov.tr/ PreHaberBultenleri.do?id=15844 laccessed 4 Dec 2013).

2. Sharp T, Moran E, Kuhn I, Barclay S. Do the elderly have a voice? Advanced care planning discussions with frail and older individuals: a systematic literature review and narrative synthesis. Br J Gen Pract 2013; DOI: 10.3399/ bjgp13X673667.

3. Eynon T, Lakhani MK, Baker R. Never the right time: advance care planning with frail and older people. $\mathrm{Br}$ $J$ Gen Pract 2013; 63(615): 511-512.

4. Kahveci R. A step towards democratization of health care services: patient involvement in terminal life support decisions. [ln Turkish]. Turkiye Klinikleri J Med Ethics 2007; 15: 90-93.

\section{Why all GPs should be bothered about Billy}

The 2014-2015 QOF overhaul' retires three critical cardiometabolic indicators from the severe mental illness (SMI) domain, keeping only blood pressure. Yet cardiovascular disorders, rather than suicide, remain the single biggest contributor to $15-20$ years reduced life expectancy. Two decades of cardiometabolic risk prevention has successfully reduced cardiovascular mortality in the general population but sadly eluded those with SMI. ${ }^{2}$

Potentiallymodifiablecardiometabolicrisks, often appearing within weeks of commencing antipsychotics, ultimately translate into 1.5-3fold increased rates of diabetes, obesity, and dyslipidaemia than in the general population. By age 40 years metabolic syndrome becomes four times commoner and about $40 \%$ of individuals are biochemically at high risk of diabetes. Furthermore the National Audit of Schizophrenia ${ }^{3}$ found only 29\% of 5091 patients from across England and Wales had cardiometabolic risk adequately assessed in the previous 12 months (weight, smoking status, glucose, lipids, BP). Weight was unrecorded in $43 \%$. Moreover when cardiometabolic complications are discovered, too often these are ignored in clinical practice particularly when compared with patients without mental illness.

Responding to this evidence of inequalities in care, the Lester Positive Cardiometabolic Resource $^{4}$ embraced these to-be-retired QOF measures with the message 'Don't just screen, intervene'. This was endorsed by the RCGP/RCPysch/RCP/RCN/Rethink/Diabetes UK and recommended by NICE (NICE CG 155) and the Schizophrenia Commission. The resource's lead author, the late Professor Helen Lester, key scientific advisor to the QOF until her death this year, challenged us to be 'Bothered about Billy' in the RCGP James McKenzie Lecture 2012.

QOF aims to universalise good quality care. The challenge is in its translation from checklist to the human being in front of us. Has anyone explained to a real person with $\mathrm{SMI}$ or their relatives why these indicators are being removed? Ultimately our responsibility is to First do no harm and provide a service that makes sense. This decision does neither.

We would ask the 2014-2015 GP contract negotiators to join us in being bothered about Billy too.

\section{Carolyn Chew Graham,}

GP Manchester, Professor of General Practice Research, Keele University, and RCGP Curriculum Guardian, Mental Health.

\section{Anand J Chitnis,}

Chair and Mental Health Lead, Solihull CCG.

\section{Paul Turner,}

GP Karis Medical Centre Birmingham; Mental health and wellbeing lead for Edgbaston network Birmingham South Central CCG.
Alex J Mitchell,

Consultant Psychiatrist, University of Leicester.

Sheila Hardy,

Education Fellow, UCL, Partners and Visiting Fellow, University of Northampton.

David Shiers,

Retired GP North Staffordshire and carer of daughter with schizophrenia.

E-mail: david.shiersladoctors.org.uk

\section{Competing interests}

David Shiers is a current member of the Guideline Development Group for NICE guidance for adults with psychosis and schizophrenia; David Shiers and Carolyn Chew Graham are members of NCCMH board

\section{REFERENCES}

1. BMA. General practice contract changes 2014-2015. http://bma.org.uk/news-views-analysis/generalpractice-contract/qof-changes-2014 laccessed 4 Dec 2013).

2. Brown S, Kim M, Mitchell C, Inskip H. Twentyfive year mortality of a community cohort with schizophrenia. Br J Psychiatry 2010; 196: 116-121.

3. Royal College of Psychiatrists. Report of the National Audit of Schizophrenia (NAS) 2012. London: Healthcare Quality Improvement Partnership, 2012.

4. Lester H, Shiers DE, Rafi I, et al. Positive Cardiometabolic Health Resource: an intervention framework for patients with psychosis on antipsychotic medication. London: Royal College of Psychiatrists, 2012

5. Lester H. The James Mackenzie Lecture 2012 Bothering about Billy. Br J Gen Pract 2013; DOI: 10.3399/bjgp13X664414

\section{DOI: 10.3399/bjgp14X676339}

\section{Improving out-of-hours handovers}

As a recently qualified academic GP working out-of-hours $(\mathrm{OOH})$ shifts, I read with interest the debate and analysis section of the October $B J G P$ dedicated to the problem of $\mathrm{OOH}$ service provision. How should urgent primary care be provided? Who are the key players and how should they form an effective $\mathrm{OOH}$ team? Dr Drinkwater pointed out the two key areas where patients can actively help in alleviating pressure on $\mathrm{OOH}$ services: self-management and information. Dr Greenhow emphasised creating a national quality contract running through all providers to ensure coherent clinical governance. Professor Mason 